\title{
IoT-enabled Emergency Information Supply Chain Architecture for Elderly People: The Australian Context
}

Asif Qumer Gill (corresponding author)

Nathan Phennel

Dean Lane

Vinh Loc Phung

\section{Address (Correspondence):}

School of Software

Global Big Data Technologies Centre

University of Technology Sydney (UTS)

Broadway, NSW 2007, Sydney, Australia.

Office: CB 11.07.119

Phone: $+61 \quad 295147938$

Fax: $\quad+61295144535$

Email: asif.gill@uts.edu.au

\begin{abstract}
The effective delivery of emergency information to elderly people is a challenging task. Failure to deliver appropriate information can have an adverse impact on the well-being of the elderly people. This paper addresses this challenge and proposes an IoT-enabled information architecture driven approach, which is called "Resalert". Resalert offers IoT-enabled emergency information supply chain architecture pattern, IoT device architecture and system architecture. The applicability of the Resalert is evaluated by the means of an example scenario, a portable Raspberry Pi based system prototype and user evaluation. The results of this research indicate that the proposed approach seems useful to the effective delivery of emergency information to elderly people.
\end{abstract}

Keywords: E-government; Emergency Information Management; Information Architecture; Internet of Things (IoT); Smart Technology

\section{Introduction}

Australia is a disaster prone country and the effective delivery of emergency information notification to affected residents is critical and challenging, especially to those who represent the elderly population (Foster 2013; Oloruntoba 2013). The major challenges are around message delivery, comprehension, and ensuring that the message is acted upon (RMIT 2011; Fan et al. 2014; Othman et al. 2014). Failure to address these challenges may have an adverse impact on the wellbeing of the elderly people. This paper addresses part of this issue and focuses on the following research question: 
How to enable the effective delivery of emergency information notification to elderly people in the Australian context?

This research employs a constructive design research approach (Duffy and O'Donnell 1998) and develops the Internet of Things (IoT) enabled architecture driven approach (Wang 1997) containing the (1) IoT-enabled information architecture pattern and (2) system architecture for the effective emergency information notification delivery to elderly people, which is deemed as a gap in the current emergency information notification delivery infrastructure. IoT is a "dynamic global network infrastructure with self-configuring capabilities based on standard and interoperable communication protocols where physical and virtual 'things' have identities, physical attributes, and virtual personalities, use intelligent interfaces, and are seamlessly integrated into the information network" (Bojanova 2015). The proposed novel IoT-enabled approach is called here "Resalert". The Resalert approach is evaluated by the means of an example scenario and an implementation prototype. The Resalert aims to guide the delivery of emergency information to elderly residents in a meaningful and effective manner.

This paper is organized as follows. Firstly, it discusses the research method and limitations. Secondly, it presents the literature review to provide the theoretical foundation and research motivation. Thirdly, it discusses the IoT-enabled information architecture driven approach Resalert. Fourthly, it evaluates the applicability of the proposed Resalert by the means of an example scenario and a portable Raspberry Pi device based system implementation prototype. Finally, it discusses the research results before concluding.

\section{Research Method and Limitations}

The focus of this research is the development and evaluation of the Resalert. Therefore, this research adopted a design research (DR) approach (Duffy and O'Donnell 1998). DR is concerned with the design and evaluation of a product or an artefact in response to some real or perceived problem (Carvalho, 2012). The newly realised artefact could be a sole contribution of the research, however, the knowledge gained from the novel artefact design is also an important contribution. The DR approach (Duffy and O’Donnell 1998) is organized into following three main steps:

1. Literature Review -Related literature is reviewed to identify the research problem within the domain of emergency information delivery to elderly people in the Australian context.

2. Design - An IoT-enabled information architecture driven approach, Resalert, is designed to address the problem identified in literature. 
3. Evaluation - Applicability of the proposed Resalert approach is evaluated with the help of an example scenario, a portable Raspberry Pi device based system implementation prototype and user evaluation. The prototype is offered as a proof of concept to guide further research and development in this important area of research.

The scope of the Resalert is limited to the delivery and presentation of emergency information to elderly people. The items such as information generation, processing, analysis or measurement of the information itself are beyond the scope of this research paper. It is intended that the emergency information can be sourced from existing emergency information warning systems that adhere to the state guidelines (Attorney-General's Department 2013a-c). Since the research project scope is to focus on only elderly people, therefore, special consideration is given to non-functional requirements such as user-friendliness and ease of use for elderly people. This research complements the prior research that highlights the information relevance: getting information to the right people, at the right time, to the right location (Gill and Bunker 2012). Additionally, this research adopts the typical standard of elderly classification as followed by the UN along with many other institutions, i.e. 60+ years old (UN 2012). The terms, "elderly residents," "seniors," "the old," "the ageing population," and "the elderly people" are used interchangeably to describe the primary target user demographics for the proposed Resalert.

The significance of this research and the proposed Resalert can be illustrated from three perspectives. Firstly, it can be linked to the need of developing novel IoT-enabled information architecture design pattern in the context of elderly population. Secondly, Australia has a high occurrence of emergencies, which has prompted the development of better or alternate emergency information notification architecture for enabling effective communication to affected residents (Gill and Bunker 2012). Thirdly, the ageing population and the emergency information notification delivery architecture have not been extensively covered in the literature. This research is an attempt to fill this small gap of research in the Australian context. Although, this research project was proposed and conducted in the Australian context, it is anticipated that other countries may find the findings of this research useful for their local context.

\section{Literature Review}

Australia has historically witnessed some catastrophic disasters, which not only caused extensive property damage but also caused loss of life (e.g. the Black Saturday bushfires of Victoria in 2009 killing 173 people; and the Queensland floods in 2010-2011 claiming 33 lives) (Holmes 2012; The Government of Victoria 2010). Communities are warned about emergencies by a group of agencies, 
known as warning originators, mostly comprised of Commonwealth agencies and Emergency Service Agencies (ESA) (Middelmann 2007; Lee et. al. 2012).

The complexity of multi-agency response and emergency warning information (to be sourced and disseminated) can lead to possible delays, miscommunications, warning message replication and ineffective response (Fan et al. 2014).

There are a number of emergency information warning systems. For instance, Emergency Alert (EA) is a national telephone-based emergency information warning system (EA 2014). EA was introduced in 2009 and uses landline and mobile telephones to relay emergency information from several authorised emergency agencies to those in affected areas (e.g. SMS to mobiles and voice messages to landlines) (Torrens Resilience Institute 2011). The Early Warning Network (EWN) is a mobile-based solution that provides subscribers with emergency information alerts (EWN 2014). In addition to traditional emergency warning information systems, a new crowdsourcing ways of emergency information sourcing and sharing are emerging (Gill 2015). Crowdsourcing is a collaborative way to source and share information in order to solve an individual, community or organisational problem (Pedersen et al. 2013). There is also a growing interest among industry, government and communities to develop IoT enabled smart architectures and systems. For instance, recently an IoT-enabled architecture has been developed for smart healthcare systems (Catarinucci et al. 2015). The emergence and widespread use of crowdsourcing (e.g. Gill et al. 2014) and smart devices such as IoT (e.g. tablets, GPS and various sensors) offer new ways of emergency information delivery (Adam et al. 2012).

The future for many Australians, old and young, is likely to be much 'smarter'. 'Smart' technology adoption is expected to hit homes in Australia with the implementation of the National Broadband Network scheme for high speed Internet. The scheme is currently being rolled out across the nation and will likely continue over the period of next 10 years (NBN Co 2014). The applicability of smart technologies is being researched for a number of contexts (Australian Academy of Technological Sciences and Engineering 2010). The application of smart technologies aimed at older generations has typically been broken down into the broad categories of: smart-homes, robotics, virtual reality, telemedicine and social connection (Morris et. al. 2012; IDC 2014).

It can be observed here that there are a number of emerging technologies and trends. The emergency information warning originators need to adopt appropriate warning technologies to effectively deliver emergency information to affected elderly people including those with 
disabilities or special needs (Lee et. al. 2013). It has been reported that agencies are faced with a number of barriers, in particular, the effective delivery of warning information to special needs and elderly people (GovDelivery 2014). Special need challenges of elderly people may include visual or hearing impairment or simply not having the knowhow of appropriately receiving warning information messages. There is a need to understand and address the elderly user context and the unique challenges they face during an emergency situation including new technology adoption challenges (Saunders 2004; UN 2012).

The IoT movement is predicted to experience rapid growth in the coming years. IoT-enabled emergency information warning systems and solutions can be developed using inexpensive devices and adopted for disseminating emergency warning information or notification to elderly user context. However, architecting and developing such dynamic and complex emergency information systems for elderly audience is an arduous task (Gill et al. 2014). Academic research is required to develop new or alternate ways or patterns of architecting and developing IoT-enabled emergency information warning or notification systems addressing the special concerns of elderly people (Pederson et. al. 2013). Hence, having the above-mentioned challenges in mind, we have developed an IoT-enabled information architecture driven approach, Resalert, which is discussed in the following section.

\section{The Resalert}

The Resalert name encompasses the primary functional aspects of the proposed approach: sending emergency information alerts to elderly people affected by a disaster or emergency. This approach offers the IoT-enabled emergency information supply chain architecture pattern (IESCAP), IoT device architecture (DA) and system architecture (SA) for guiding the architecture-driven development of the emergency information notification system for the effective delivery of emergency information to elderly people.

\section{1 loT-enabled Information Architecture Pattern}

An architecture pattern is used to illustrate the way in which to build something (Vaishnavi and Kuechler 2007) and can be described using the viewpoint template. The real value is the reusability of the architecture pattern to solve related or similar problems (Chessell and Smith 2014). The information management framework from Chessell and Smith (2014) has been used to develop the IoT device enabled IESCAP architecture pattern for the identified challenge of emergency information delivery to elderly people. This framework provides a structured approach and pattern viewpoint template, which have been used to the development of the following five views of the IESCAP. A viewpoint is a template or blueprint that can be used to create a view. Each view of the 
IESCAP pattern is organised by using the four parts of the architecture pattern viewpoint template (Chessell and Smith 2014): context, problem, solution and consequences. The following five IESCAP pattern views are explained in a tabular format (see Tables 1-5).

Table 1. SMS to Display over Bluetooth/Wi-Fi

\begin{tabular}{|c|c|}
\hline $\begin{array}{l}\text { 1. Pattern View } \\
\text { Name }\end{array}$ & SMS to Display over Bluetooth/Wi-Fi \\
\hline 1. Context & $\begin{array}{l}\text { Agencies send warning information to affected elderly users via SMS text } \\
\text { message. }\end{array}$ \\
\hline 2. Problem & $\begin{array}{l}\text { Elderly users may overlook the SMS message, especially when sight } \\
\text { impairment is present. }\end{array}$ \\
\hline 3. Solution & $\begin{array}{l}\text { Redistribute the existing SMS messages received via Bluetooth or Wi-Fi to the } \\
\text { IoT-enabled Resalert that can display the warning information suitable to the } \\
\text { elderly user context. }\end{array}$ \\
\hline - Description & $\begin{array}{l}\text { The pattern diagram uses arrows to indicate the path of the emergency } \\
\text { information warning message. The cloud represents the originators (e.g. } \\
\text { agencies). The message is sent to telephone numbers with registered locations } \\
\text { in the affected area. These originators then distribute the message through the } \\
\text { cellular network such as SMS. The message is received as an SMS on the } \\
\text { resident's mobile phone equipped with software used for triggering an external } \\
\text { display using the Resalert. Android and iOS support Virtual Network } \\
\text { Computing could potentially be leveraged to support this feature. }\end{array}$ \\
\hline - Diagram & Originator \\
\hline 4. Consequences & $\begin{array}{l}\text { The messages sent from any source could be presented to the affected resident } \\
\text { in a format appropriate to the need of elderly user. } \\
\text { The number of hops from device to device that a message must traverse before } \\
\text { reaching the user is high and each hop increases the likelihood of non-delivery } \\
\text { or dropped messages }\end{array}$ \\
\hline
\end{tabular}

Table 2. SMS to Mobile Application

\begin{tabular}{|l|l|}
\hline $\begin{array}{l}\text { 2. Pattern View } \\
\text { Name }\end{array}$ & SMS to Mobile Application \\
\hline 1. Context & $\begin{array}{l}\text { Agencies send warning information to affected elderly users' smartphone } \\
\text { mobile application. }\end{array}$ \\
\hline 2. Problem & Similar to pattern 1. \\
\hline 3. Solution & $\begin{array}{l}\text { Redistribute the existing SMS messages received on a smartphone mobile } \\
\text { application to the IoT-enabled Resalert over the Internet. }\end{array}$ \\
\hline - Description & $\begin{array}{l}\text { This pattern illustrates that a warning information message is sent through the } \\
\text { cellular network, as SMS, to a mobile smartphone application. Once the } \\
\text { message is received on a smartphone application, the message can be } \\
\text { retransmitted through the smartphone's Internet connection to the 'Resalert', } \\
\text { which serves the message content to the end user in a more customizable } \\
\text { format. }\end{array}$ \\
\hline
\end{tabular}




\begin{tabular}{|l|l|}
\hline $\begin{array}{l}\text { 2. Pattern View } \\
\text { Name }\end{array}$ & SMS to Mobile Application \\
\hline - Diagram & Sms to Mobile Application \\
\hline Originator Consequences & $\begin{array}{l}\text { This pattern also offers more control regarding the presentation of messages. } \\
\text { The message can be reformatted by the mobile application to allow for easier } \\
\text { interpretation. It requires the user to have a smartphone, to have downloaded } \\
\text { the application, and have cellular signal at the time of emergency }\end{array}$ \\
\hline
\end{tabular}

Table 3. SIM-Equipped Device

\begin{tabular}{|c|c|}
\hline $\begin{array}{l}\text { 3. Pattern View } \\
\text { Name }\end{array}$ & SIM Equipped Device \\
\hline 1. Context & Agencies send SMS messages to affected elderly residents. \\
\hline 2. Problem & Similar to patterns 1 and 2. \\
\hline 3. Solution & $\begin{array}{l}\text { Forward warning information messages directly to a SIM-equipped Resalert } \\
\text { system to minimise the amount of hops between source and destination while } \\
\text { still allowing for customisation of message presentation. }\end{array}$ \\
\hline - Description & $\begin{array}{l}\text { Forward warning information message directly to elderly user's Resalert } \\
\text { system directly, which is equipped with a SIM card. The SIM is registered to } \\
\text { the elderly user and details about the location of the device are available to } \\
\text { allow for agencies to determine which Resalert elderly people devices are in an } \\
\text { affected emergency area. The Resalert system receives the message directly } \\
\text { from the source agency and presents the information in a format that is } \\
\text { appropriate to the elderly user's special needs and the type of emergency. }\end{array}$ \\
\hline - Diagram & Originator $\quad$ Cell Tower \\
\hline 4. Consequences & $\begin{array}{l}\text { Improved delivery and presentation of information to elderly people. The } \\
\text { system is quite autonomous and doesn't require any additional connections, } \\
\text { hops, mobile application and server as found in other two patterns. Mobile } \\
\text { signal is required for the system to operate. }\end{array}$ \\
\hline
\end{tabular}

Table 4. Landline Interception

\begin{tabular}{|l|l|}
\hline $\begin{array}{l}\text { 4. Pattern View } \\
\text { Name }\end{array}$ & Landline Interception \\
\hline 1. Context & $\begin{array}{l}\text { Agencies send emergency warning information messages through an } \\
\text { automated landline alert. }\end{array}$ \\
\hline 2. Problem & $\begin{array}{l}\text { Voice message is limited to a concise verbal message and may incorrectly take } \\
\text { emergency information as something else. Users can easily overlook a voice } \\
\text { message. }\end{array}$ \\
\hline 3. Solution & $\begin{array}{l}\text { Intercept the incoming warning messages from the landline and republish the } \\
\text { information using Resalert allowing a higher level of message customization. }\end{array}$ \\
\hline
\end{tabular}




\begin{tabular}{|l|l|}
\hline $\begin{array}{l}\text { 4. Pattern View } \\
\text { Name }\end{array}$ & Landline Interception \\
\hline - Description & $\begin{array}{l}\text { The Resalert system is installed in the home and connected to the landline. It is } \\
\text { activated when a landline call is received from an identified emergency } \\
\text { telephone number. To display clear information, the voice message is } \\
\text { converted to text to provide a visual warning message that can be tailored to } \\
\text { the needs of the affected resident or to meet the context of the disaster at hand. }\end{array}$ \\
\hline - Diagram & $\begin{array}{l}\text { Landline Interception } \\
\text { Originator }\end{array}$ \\
\hline 4. Consequences & $\begin{array}{l}\text { This pattern takes advantage of the fact that many older residents will likely } \\
\text { have a landline registered in their name that is also linked to their location. } \\
\text { Poor voice to text translation could lead to incorrect or ambiguous warning } \\
\text { information. }\end{array}$ \\
\hline
\end{tabular}

Table 5. Web-based System

\begin{tabular}{|c|c|}
\hline 5. Pattern Name & Web System \\
\hline 1. Context & $\begin{array}{l}\text { Agencies send warning information messages over the internet to affected } \\
\text { residents. }\end{array}$ \\
\hline 2. Problem & Residents would need to actively seek out information during an emergency. \\
\hline 3. Solution & $\begin{array}{l}\text { Use a web-based system to consolidate disaster information from various } \\
\text { sources and relay directly to affected residents via an Internet-connected IoT } \\
\text { Resalert system installed in their home. }\end{array}$ \\
\hline - Description & $\begin{array}{l}\text { The pattern consolidates warning messages available via the Internet from } \\
\text { originators to relay warning messages to the end user in a more appropriate } \\
\text { format. This method of redelivery facilitates customisation suitable to elderly } \\
\text { user and emergency context. }\end{array}$ \\
\hline - Diagram & 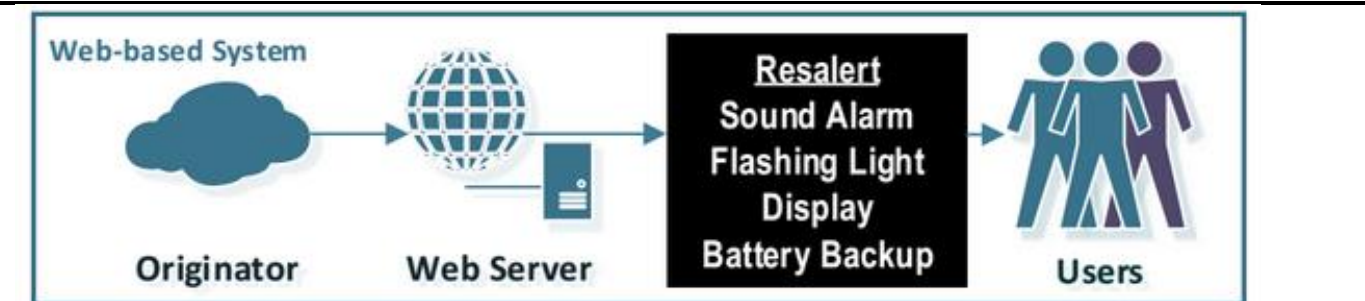 \\
\hline 4. Consequences & $\begin{array}{l}\text { The affected resident receiving the message is given a single, more reliable link } \\
\text { to the emergency information. The information is timely, presented } \\
\text { appropriately and is pushed to the user. Fewer hops are required between source } \\
\text { and destination of a warning message. Additional maintenance of the web server } \\
\text { and reliability of the IoT devices could be the key concerns. }\end{array}$ \\
\hline
\end{tabular}

Tables 1-5 present five views of the reusable IoT-enabled emergency information supply chain architecture pattern, which can be tailored and implemented to develop specific IoT-enabled information systems. 


\subsection{The Resalert loT Device Architecture}

The core and common to all the proposed architecture pattern views (highlighted as a black box Tables 1-5) is the Resalert system IoT device. This section further discusses the details of the Resalert device architecture design, which needs to be installed in the elderly users' home. There are a number of possible configurations of the Resalert IoT device architecture. Three relevant architecture design options for the Resalert IoT device are shown below:

- Option A: TV + Light + Speaker + NBN + Computer

- Option B: Projector + Light + Speaker + Battery Backup + NBN + Computer

- Option C: Digital Picture Frame + Light + Speaker + Battery Backup + NBN + Computer

All the options have some common components such as all the Resalert IoT devices have a compute component (e.g. Raspberry Pi) to be connected to the Internet, and therefore use the most reliable Internet connection such as the National Broadband Network (NBN). Each option also features a light and sound alert (connected to a compute component) for elderly users with hearing and visual impairments, respectively. The main variation in each option is the display (e.g. TV or projector) that is required to display the detailed emergency information to the user. Based on the review of the available options, the research project team favoured design $\mathrm{B}$, which uses a low voltage pocket projector. Figure 1 presents the Resalert IoT device architecture with essential components. The Resalert IoT device needs to be installed in the elderly users' home to support the proposed IoT-enabled emergency information supply chain architecture pattern views.

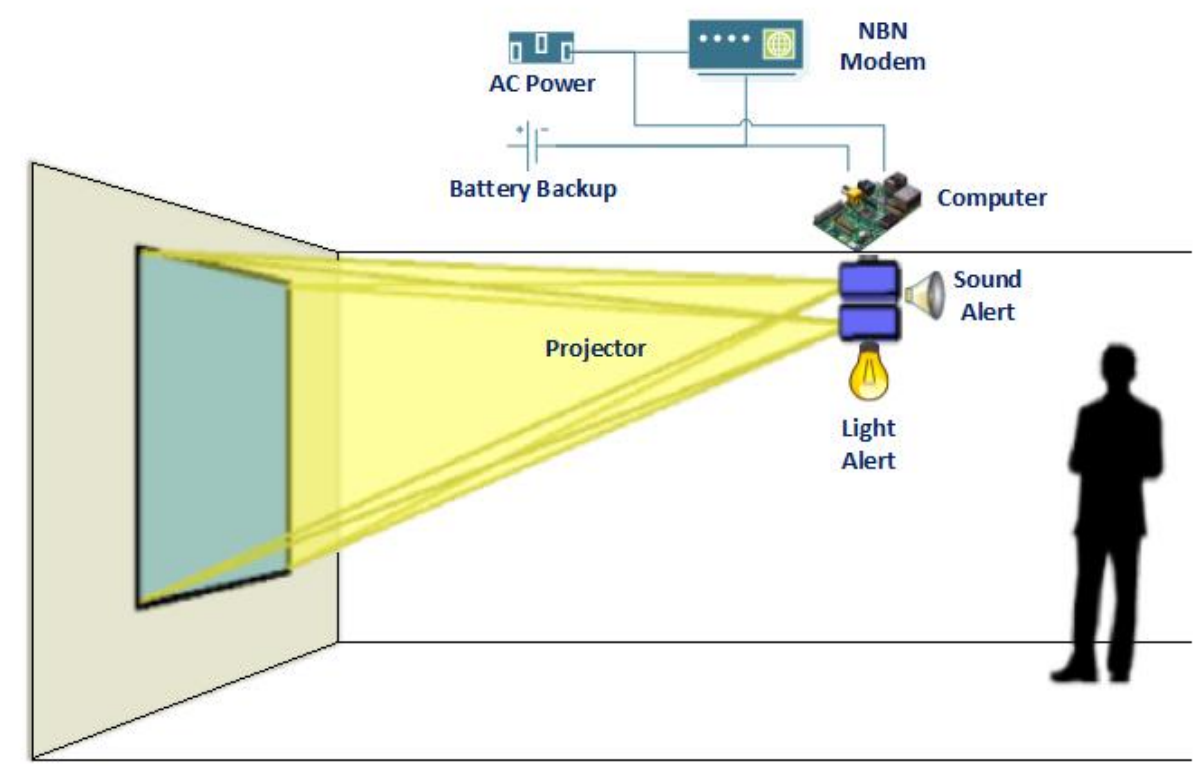

Figure 1 - The Resalert IoT Device Architecture 


\subsection{The Resalert Notification System Architecture}

The proposed IoT-enabled architecture pattern can be realized by the system architecture. A highlevel emergency information notification system architecture (Figure 2) is provided to show the end-to-end flow of the emergency information for the proposed information supply chain architecture pattern. Figure 2 illustrates how the information is mapped between different sources to produce the appropriate emergency message information delivery flow or algorithm for the elderly people.

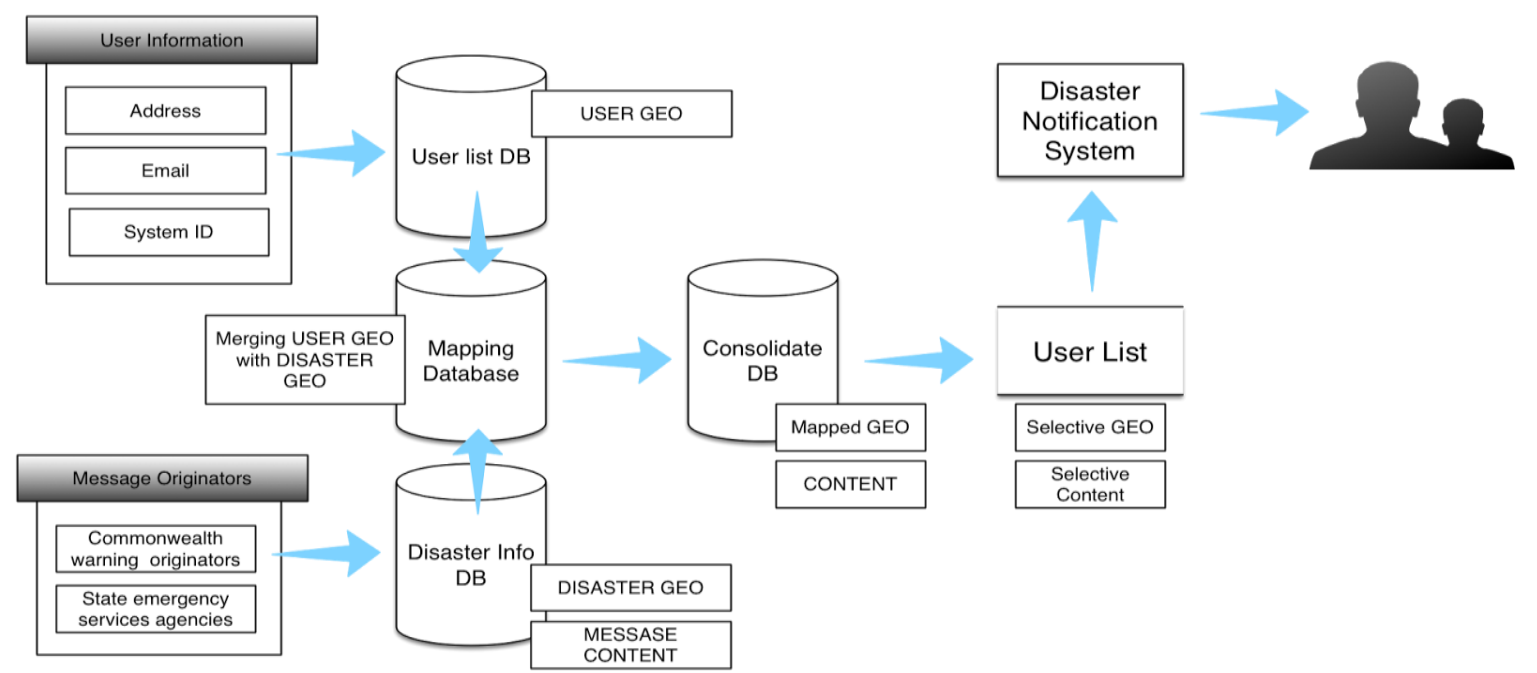

Figure 2. Notification System Architecture

Firstly, we need to setup a "User list DB" database and store the personal details of the intended elderly people such as address, email and system ID. The system ID is associated with an IoT device to remotely connect, monitor and maintain the system installed in the elderly user home. This could be implemented using a specified port and IP address, or socket. Secondly, we need to setup a "Disaster Info DB" database to store available emergency or disaster information, which is received from the authorised organizations such as warning originators. Thirdly, these two databases need to be mapped and stored in a "Mapping Database" based on user and emergency location data. Fourthly, the mapped data is loaded into a consolidated database "Consolidate DB". We need a consolidated database, which contains user information mapped with emergency warning information message contents. This allows to send the relevant emergency warning information message to only those elderly people who are impacted by the emergency. The emergency warning information message will follow certain formats and contain appropriate information such as type of disaster or emergency, time, location, guidance, notice, future plan, and other information depending on the situation. Finally, once the message is linked to the users and is ready to be sent, the disaster notification system will dispatch it to the relevant elderly users as 
identified in the "User List" from the consolidated database. The message delivery steps are detailed in the following algorithm.

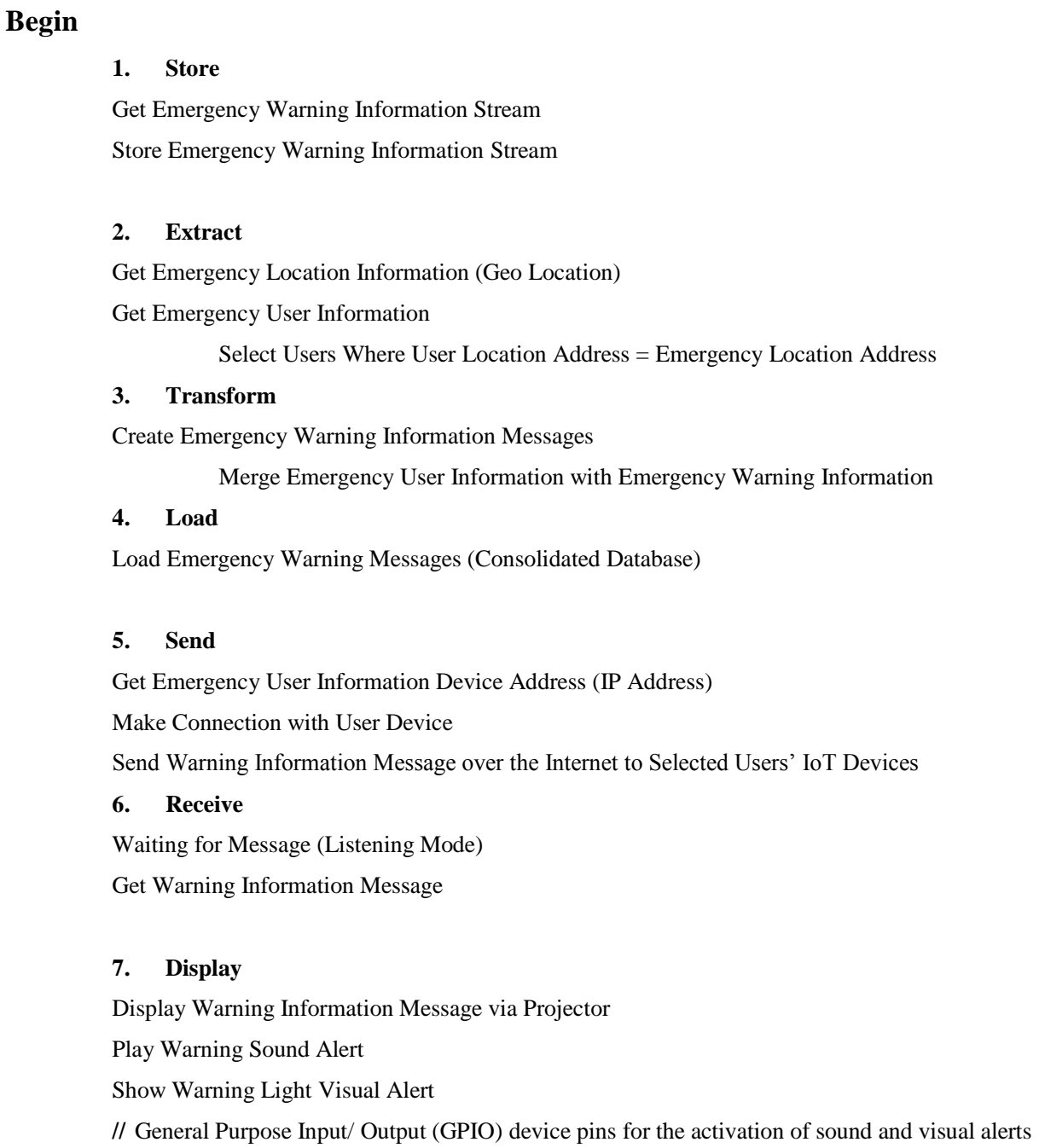

8. $\quad$ Reset

Rest Device

//Push 'Reset' button for deactivating the alert and returning the device to a listening state

End

\section{Application}

To illustrate how the proposed IoT-enabled Resalert approach will work in an emergency situation, an example scenario is constructed and explained in this section. Firstly, the emergency event for the example scenario and the fictional elderly user are detailed. Secondly, the fictional elderly user is put into Scenario 'A', in which the elderly user has no access to IoT-enabled Resalert, and in Scenario 'B', elderly user has access to IoT-enabled Resalert installed in his home. 


\subsection{Emergency Event}

There are bush fires in the Blue Mountains area of NSW, Australia. They are first reported at midday on the TV news. During the evening, extreme winds feed the fire and a decision is made to send an official emergency information warning message advising anyone in or near the town of Leura to evacuate their property and head to nearby Katoomba. Ken is 80 years old and lives on a property on the edge of the village called Leura in the Blue Mountains area of NSW. He has poor hearing and has limited mobility. He has a television, radio and landline telephone, which are his only means of receiving emergency information. His property is only accessible through a single $500 \mathrm{~m}$ driveway.

\subsection{Scenario A - Without Resalert}

Ken is watching the news before he goes to bed and sees a warning regarding bushfires in the area. The news report mentions that the fires are largely under control. Ken has been living in the area for many years without any issues, he heads to bed without any worry. Ken's landline phone is in the lounge and, upon heading to bed, he takes a wireless handset into the bedroom. While Ken is sleeping, the power fails just before the emergency information message is sent to his landline by the agency advising that he should evacuate the area. Unfortunately, the power outage renders the wireless phone inoperable. As Ken is hard of hearing, he does not hear the phone ringing downstairs and the message goes unnoticed.

\subsection{Scenario B - With Resalert}

Ken agreed to have a new IoT-enabled alert system, "Resalert with the projector display", which is installed on his property. Setup involved connecting the system to the new National Broadband Network. The Resalert can take the emergency information from the originator and display it on the wall via the connected projector (see Figure 1 - option B). Installation was quick and the device requires no maintenance from Ken. He soon forgets that the system is even in place. Ken heads to bed after hearing a warning of bushfires in the area but does not expect to be affected. In the night, Ken is woken by a loud alert and, without picking up his glasses; he makes his way downstairs to investigate. Upon entering the lounge, he can see a clear large message on the wall stating there is an incoming bushfire nearby and that he should immediately evacuate. He then phones the emergency line as indicated on the screen and due to his limited mobility an ambulance is sent to evacuate Ken to a nearby town. This scenario demonstrates the applicability and value of the proposed IoT-enabled Resalert. 


\section{Prototype Implementation and User Evaluation}

A proof of concept prototype has been developed for user evaluation to further analyse the practical applicability of the proposed IoT-enabled Resalert approach (see Appendix A-D). Due to this research project constraints (e.g. time, funding, and general feasibility), the proof of concept prototype was developed using only inexpensive IoT device components for the Resalert. This is because these components can be easily obtained in the Sydney metro area or from online retailers. One of the assessors, from the University of Technology Sydney (UTS), of this project played the role of the elderly user and evaluated the prototype using the formal UTS evaluation criteria (see Appendix D). It is assumed for this prototype implementation and user evaluation that the location of the elderly user would be available from the existing government registry such as Census Data, Human Services Department, or phonebook. Therefore, determining user location is out of scope for this prototype. We assume that the proposed system is aware of the location of each deployed IoT device. The National Broadband Network (NBN) will serve as a fundamental component to enable IoT system functionality. We assume the NBN rollout will be successful and we limit IoT device application to areas with NBN connectivity.

The prototype has been developed and used for demonstrating the Resalert proof of concept that incorporated several architecture components (as discussed earlier). A Raspberry Pi Model B was used as the backbone computing capability of the IoT-enabled Resalert system. Additionally, the system used the General Purpose Input/Output (GPIO) pins of the device to power LED lights that represent the activation of sound and visual alerts that would be available to the user. For demonstration and user evaluation purposes, LED lights were fixed to a breadboard, which facilitate modelling electrical circuits. The breadboard also featured a push 'reset' button for deactivating the alert and returning the device to a listening state. An LED was also used to show that an external device, such as the projector could also be switched on and off remotely. In addition to the Resalert hardware configuration, a Hypertext Markup Language (HTML) webpage (adhered to the state republishing guidelines) was designed and implemented to display the warning message contents to the user (see Figure 3). The official sound alert, according to NSW guidelines, (Attorney-General Department 2013) was used and issued upon the activation of Resalert. Instead of a projector, for our demonstration, a large monitor was used to display the message. The lack of a projector doesn't drastically impact the proof of concept because a large screen monitor was arranged to simulate a projected image. The battery backup was not included in the demonstration prototype, due to lack of research funding, however, it could easily be purchased and implemented in future iterations of the architecture design. 


\section{SEVERE WEATHER WARNING for Heavy Rain}

\section{For people in the Southeast Coast district and parts of the Wide Bay and Burnett district}

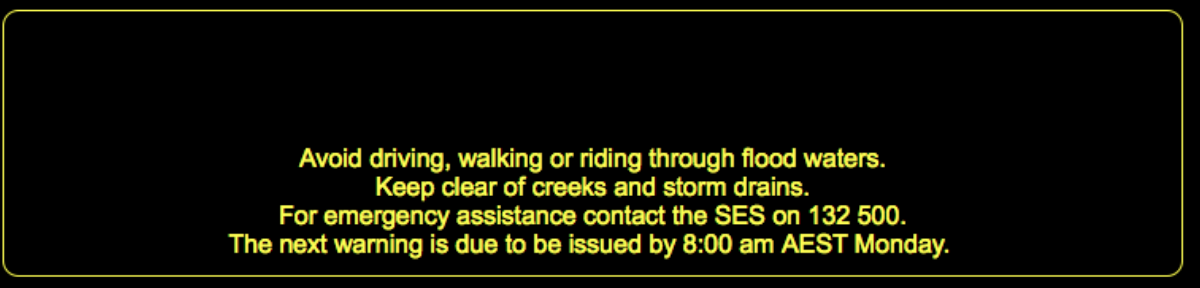

Synoptic Situation: At 6:00 am AEST, a low pressure system was located near Maryborough and moving slowly in a southerly direction. The low is expected to continue moving slowly in a southerly direction today before possibly moving in a northerly direction during Tuesday.

Heavy rain which may lead to flash flooding is expected about the Southeast Coast and south eastern parts of the Wide Bay and Burnett districts today, particularly about the Fraser and Sunshine Coasts and adjacent inland areas.

Localised 24 hour rainfall totals in excess of $150 \mathrm{~mm}$ are likely, especially about the Fraser and Sunshine Coasts and adjacent inland areas. Locations which may be affected include Fraser Island, Gympie, the Sunshine Coast, Brisbane, the Gold Coast and Ipswich.

At 6:20am AEST, the heaviest rain was located on radar near Tiaro, Glenwood, Gympie and Goomboorian. In the 2 hours to 6:20am AEST, 124mm of rainfall has been recorded at Mount Wolvi [east of Gympie].

Figure 3: The Resalert - Warning Message

For user evaluation perspective, the system was remotely activated using the Secure Shell (SSH) over a local network. Please note that the Python code combined with UNIX shell scripts were embedded into the prototype to allow SSH activation. This was done to simulate the push of warning messages to elderly user from a central location or originator. This activation triggered the GPIO pins and activated the warning alert to the elderly user including the strobe light represented as a flashing LED, the sound alert, and the projector represented by a monitor. The end result is that the elderly user is prompted by a sound alert, flashing lights, and a warning message, which remains on the screen until they reset the device. The user evaluated the prototype by using the formal user evaluation form (8 test cases with pass or fail results). The user found the system easy to use and fit for its purpose and declared all the test cases "pass". Please see Appendix D for user evaluation test cases and results. This proof of concepts and user evaluation clearly indicate the practical applicability of the proposed innovative IoT-enabled Resalert approach, which have not been discussed before. Please refer to the Appendix $\mathrm{C}$ for photos of the demonstration and user evaluation held at University of Technology Sydney (UTS), Sydney, Australia. Please see the IoT device hardware specifications, setup details and prototype Python code at the following publically available link: https://github.com/enphnt/resalert. 


\section{Discussion and Analysis}

The IoT-enabled Resalert approach seems helpful to the effective delivery and presentation of the emergency information to elderly people at a high level (e.g. sound and light alerts) and low detailed level (e.g. detailed message via projector display). This research suggests the need for at least two information architecture design components for the emergency information notification delivery: the architecture of getting the information from its source to the proposed IoT device or destination (e.g. Resalert architecture pattern views and system architecture) and how the message is presented to the elderly users of the IoT device (e.g. Resalert device architecture).

This paper presented the five information architecture supply chain architecture pattern views in order to get a warning message from a publisher to the intended users having certain device such as the Resalert IoT device. The proposed pattern views do not replace existing emergency information notification systems; rather, it shows how to leverage the existing warning systems. The research presented in this paper draws our attention to the point that the use of the existing emergency information warning systems may vary according to the incident and no single system can be used in all emergency contexts. Based on the research results, it is suggested that an IoT-enabled information supply chain architecture should be in place for consolidating and disseminating the information sourced from various distinct emergency information systems. The proposed IoTenabled emergency information supply chain architecture pattern views and system architecture show how to consolidate and disseminate information through an affordable IoT device (Raspberry Pi based Resalert device). However, it is important to follow the guidelines as outlined in the "Code of Practice for Warning Republishers" (Attorney-General's Department 2013) when designing emergency information messages to warn the residents of the encroaching emergencies. This code outlines considerations that should be taken into account in terms of accuracy, timeliness, appropriate level of information, and reliability of the contents of warning messages delivered or redelivered to the public.

This paper highlighted that a simple text message or phone call can be overlooked by elderly people - whether on a smartphone or other devices bombarded with texts, emails and updates. The elderly users may have multiple messaging systems on existing devices, which can create more opportunity for confusion or missed messages. Therefore, a personalized dedicated IoT device, as proposed in this paper (e.g. Resalert device embedded in the information supply chain architecture), may provide a clearer delivery from the user's point of view. It has been suggested that "the interface has not only to appear familiar; it also has to allow for a familiar style of interaction (for instance, by means of familiar action), fitting the elders' sensorial abilities" (Leonardi et al. 2008). The IoT- 
enabled Resalert approach, proposed in this paper, would benefit the user if it incorporates familiar design constructs found in other types of alarm systems and alerting devices (e.g. Cisco 2007).

The inexpensive Resalert IoT device seems affordable and can be easily installed in the home of elderly people, preferably in a central or common area, which is frequently used and convenient for the elderly user to access. This may help minimising the challenges related to user mobility and allow them to clearly see or hear any emergency notification (Van de Watering 2005; Cisco 2011). To address the remaining common obstacles identified in the elderly user interactions and emergency context, we included a sound alert, flashing light alert, battery backup, and a format to display the information clearly to the user. The sound alert would address problems of sight impairment and can inform users who are asleep or in another room at the time of emergency notification. It is recommended that any sound should use lower frequency ranges to accommodate for hearing impairment (Van de Watering 2005). Likewise, a flashing light would accommodate those users with hearing impairment and serve as a reliable means to inform if the affected residence is experiencing increased sound disruption as an effect of an emergency. Hence, based on the overall research results and analysis presented in this paper, it is suggested that the proposed IoT-enabled Resalert approach seems helpful and may augment existing emergency information warning systems.

\section{Related Work}

There is a considerable global interest in national emergency information notification systems and in order to provide the broader view, we looked at the related global work and initiatives. For instance, America Federal Emergency Management Agency (FEMA 2014) introduced and tested the first-ever nationwide Emergency Alert System (EAS). The EAS was tested to evaluate the readiness and effectiveness of the system to tackle the difficulties during periods of extreme national emergency. The test involved several participants including media such as radio and television broadcasters, cable, satellite, and landline providers across the country. Although the test message was successfully received by millions of Americans, several technical issues were identified for further refinement such as audio quality, state monitoring assignments and designations, and EAS device configuration (FEMA, 2014).

Similarly, in other related works, to help people respond more effectively to earthquakes, Turkish Government funded Department of Remote Sensing and Photogrammetry to develop a disaster and emergency management system, called AFAYBIS. This system is designed to make disaster information available quickly during and before catastrophic situations via different media channels 
including the Internet. This system aims to minimise possible damages by using the latest geographical information system, CBS/GIS (Eraslan et al. 2004). More recently, a group of researchers at Universidad Carlos III de Madrid (UC3M) has created a new way to dispatch emergency information to affected users by organising all available information sources (UC3M 2014). They developed a system called Simple Emergency Alerts for All (SEMA4A). The existing knowledge about emergency information can be generated faster and more efficiently to alert users by using this system. This work focuses on all the general users. The work presented in this paper complements this work and focuses specifically on elderly people with special needs, instead of everyone, in the overall Australian context.

It is evident from the related recent work that there is a clear interest and need for more research and development in this important area. The aim of this paper is to find new or alternative ways to reach out to elderly people in an emergency situation. This paper does not claim to provide an exhaustive list of IoT architecture pattern views or device or system architectures. This paper provides a foundation, direction and platform for future research. Thus, similar to other research studies, the research presented in this paper needs to be viewed from its limitations, and needs to be continuously improved and updated to address the concerns of stakeholders such as the elderly people.

\section{Conclusion}

This paper proposes a novel IoT-enabled information architecture driven approach Resalert to address the challenge of emergency information notification delivery to elderly people. This is accomplished through the IoT-enabled emergency information supply chain architecture pattern views, IoT device and system architecture. The Resalert approach provides the end-to-end information flow or algorithm - source (a disaster-warning originator) to the affected residents (elderly people). The core of the Resalert is the IoT device, embedded in the overall information supply chain and system architecture, which offers a new way to deliver the emergency information to elderly people. An exemplary scenario and a prototype is developed and used to demonstrate the applicability of the proposed new Resalert. The use of the IoT-enabled Resalert architecture will ensure that the important elements of the desired emergency information management environment are not missed for the elderly people. It is also worth to mention that the proposed approach is another way to disseminate information to elderly people and it does not replace the existing formal communication channels and systems. Based on the analysis presented in this paper, it can be suggested that the proposed IoT-enabled approach should be considered as a part of the whole solution for emergency information management. 
Appendix: Resalert IoT Prototype Implementation and User Evaluation

A. Resalert Computing Capability - Raspberry Pi Computing Device

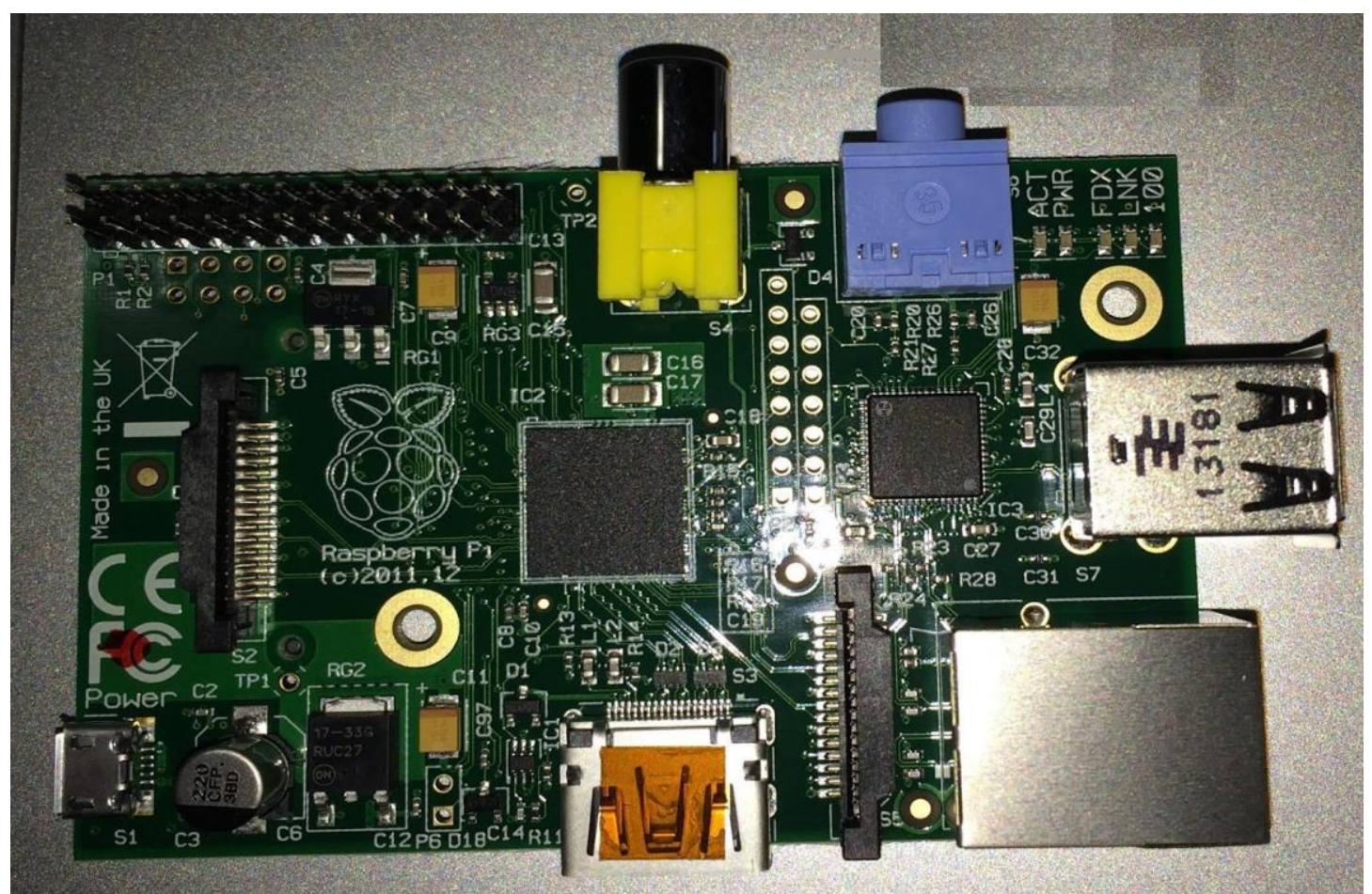

B. Resalert Configuration and Setup

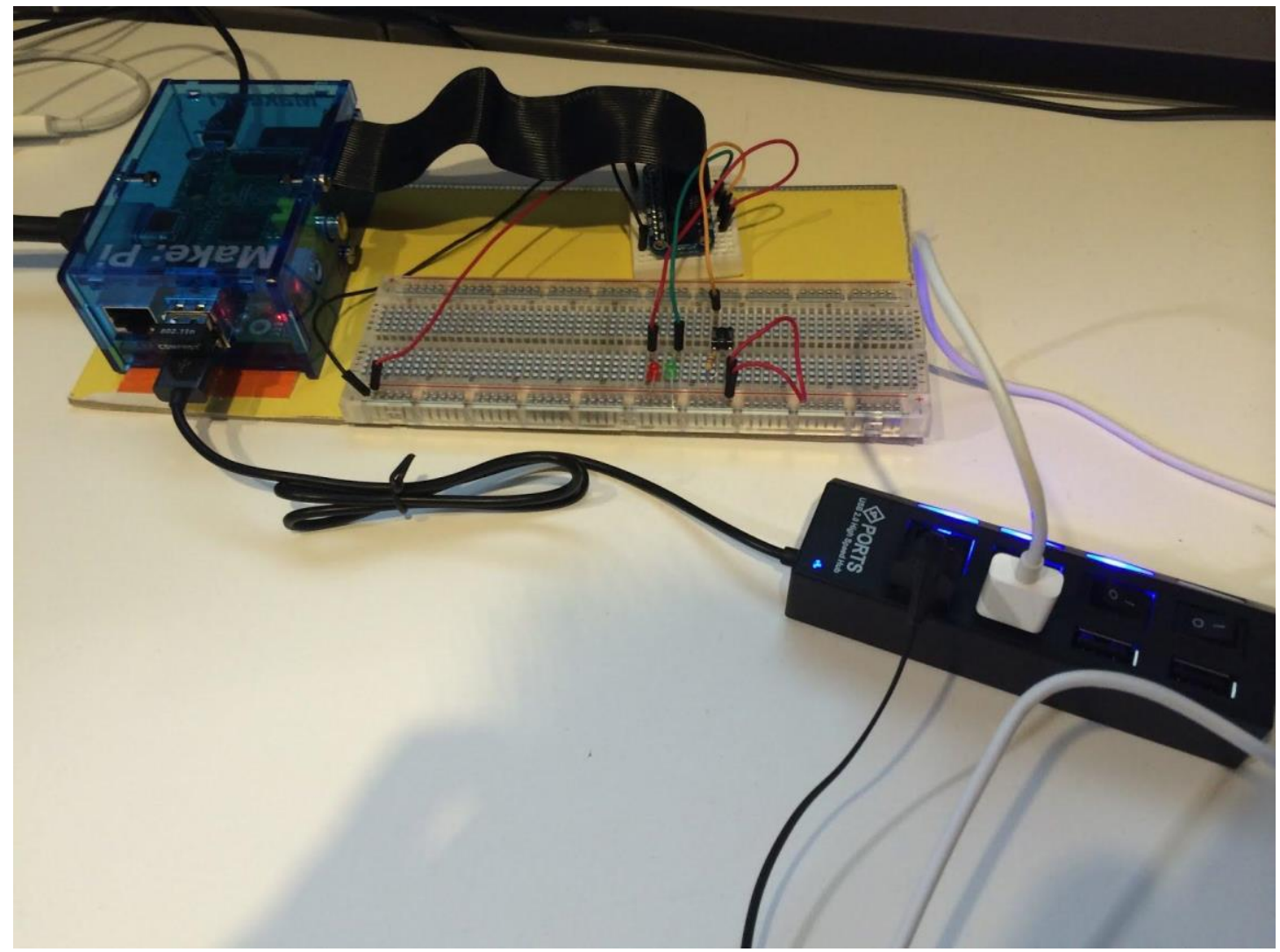




\section{Resalert Demonstration}

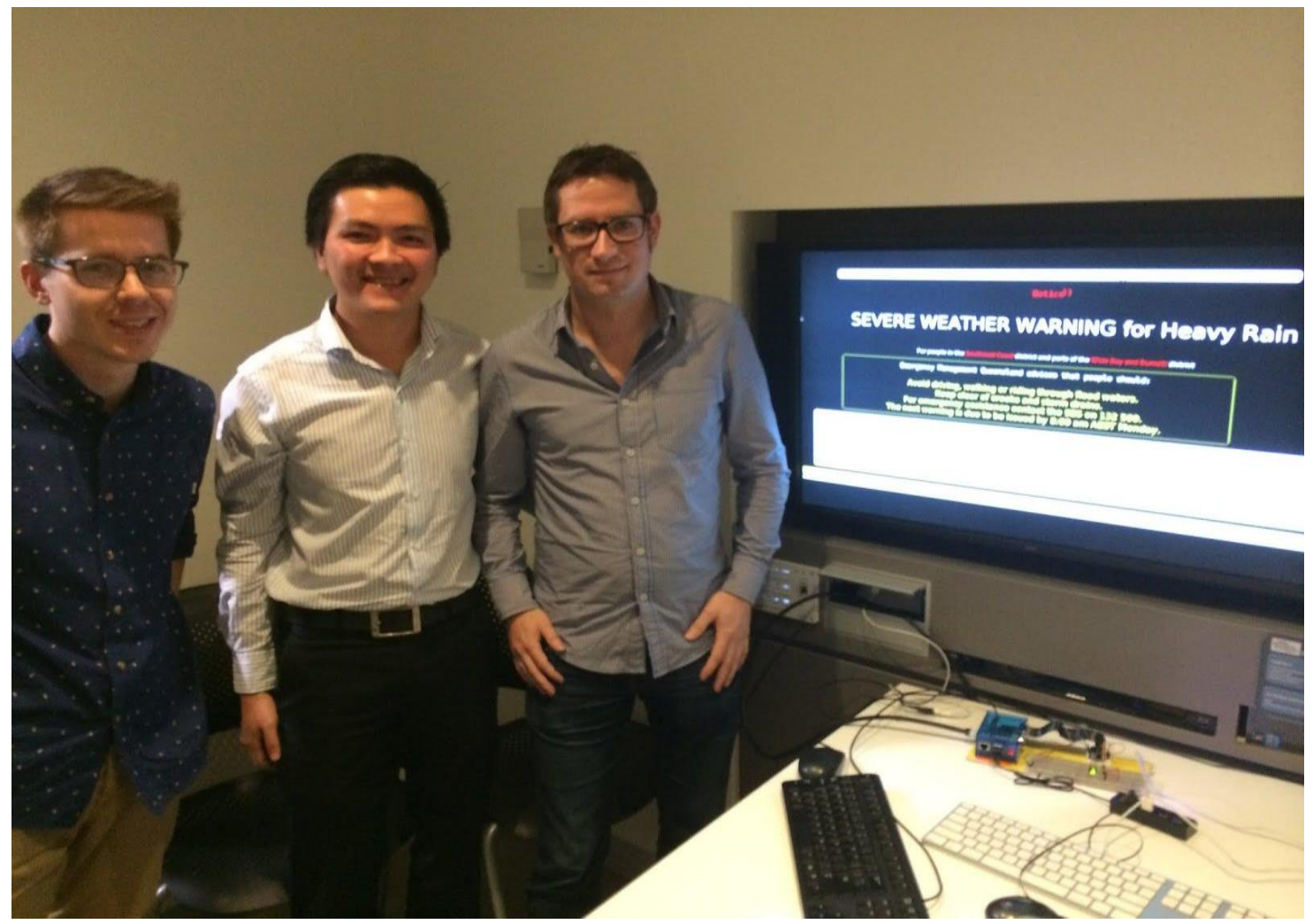

\section{User Evaluation}

The prototype has been evaluated by using the following formal University criteria for evaluating prototypes, systems, and architecture and design projects.

\begin{tabular}{|c|c|c|}
\hline Test Case ID & Evaluation Criteria & Results (Pass or Fail) \\
\hline TC001 & $\begin{array}{l}\text { It meets a demonstrated need for a clearly defined } \\
\text { purpose and identified user group. }\end{array}$ & $\sqrt{ }$ Pass \\
\hline TC002 & $\begin{array}{l}\text { It makes an original contribution and exhibits a } \\
\text { degree of innovation. }\end{array}$ & $\sqrt{\text { Pass }}$ \\
\hline TC003 & It is fit for its intended purpose - technical quality. & $\sqrt{\text { Pass }}$ \\
\hline TC004 & $\begin{array}{l}\text { It is fit for its intended purpose - quality of the } \\
\text { design. }\end{array}$ & $\sqrt{\text { Pass }}$ \\
\hline TC005 & $\begin{array}{l}\text { It is fit for its intended purpose - usability of system's } \\
\text { interface for intended users. }\end{array}$ & $\sqrt{ }$ Pass \\
\hline TC006 & $\begin{array}{l}\text { It is fit for its intended purpose - positive user } \\
\text { experience. }\end{array}$ & $\sqrt{\text { Pass }}$ \\
\hline TC007 & It fulfils the objectives of the overall research project. & $\sqrt{\text { Pass }}$ \\
\hline TC008 & $\begin{array}{l}\text { It demonstrates a degree of robustness as a result of } \\
\text { testing. }\end{array}$ & $\sqrt{ }$ Pass \\
\hline
\end{tabular}




\section{References}

Adam, N.R., Shafiq, B. \& Staffin, R. 2012, 'Spatial Computing and Social Media in the Context of Disaster Management', Intelligent Systems, IEEE, vol. 27, no. 6, pp. 90-6.

Australian Academy of Technological Sciences and Engineering 2010, Smart Technology for Healthy Longevity. Melbourne. viewed 20 April 2014 <http://www.atse.org.au/Documents/Publications/ Reports/Health\%20\&\%20Tech/Smart\%20Tech\%20for\%20Healthy\%20Longevity\%20$\% 20$ Report.pdf $>$.

Attorney-General's Department 2013a, Code of Practice for Warning Republishers. viewed 20 April 2014 <http://www.em.gov.au/Emergency-Warnings/Documents/Code\%20of\%20Practice\%20for\%20War ning\%20Republishers.doc>.

Attorney-General's Department 2013b, Communicating with People with Disability: National Guidelines for Emergency Managers, viewed 20 April 2014 <http://www.em.gov.au/Publications/Australianemerg encymanualseries/Documents/CommunicatingwithPeoplewithDisabilityNationalGuidelinesforEmerg encyManagers.PDF>.

Attorney-General's Department 2013c, Australia's Emergency Warning Arrangements, Australia, viewed 20 April $2014<$ http://www.em.gov.au/Documents/Australian\%20Emergency\%20Manageme nt\%20Arrangements.pdf $>$.

Bojanova, I. 2015. Defining the Internet of Things. http://www.computer.org/web/sensingiot/content? $\mathrm{g}=53926943 \&$ type $=$ article \&urlTitle=defining-the-internet-of-things .

Carvalho, J. 2012, 'Validation criteria for the outcomes of design research', IT Artefact Design \& Work practice Intervention, a Pre-ECIS and AIS SIG Prag Workshop, June 10, 2012, Barcelona.

Catarinucci, L.; de Donno, D.; Mainetti, L.; Palano, L.; Patrono, L.; Stefanizzi, M.L.; Tarricone, L., 2015. "An IoT-Aware Architecture for Smart Healthcare Systems," in Internet of Things Journal, IEEE, vol.2, no.6, pp.515-526, Dec. 2015. doi: 10.1109/JIOT.2015.2417684.

Chessell, M. and Smith, H. 2014, Patterns of Information Management, IBM Upper Saddle River, NJ: IBM Press.

Cisco 2007, The future of aged care. People with Disability: National Guidelines for Emergency Managers viewed 20 April 2014 <http://www.cisco.com/web/ANZ/assets/docs/smb/Cisco_AgedCare.pdf>.

Cisco 2011, "Older people, technology and community," viewed 20 April 2014 <http://www.cisco.com/ web/about/ac79/docs/wp/ps/Report.pdf>.

Duffy, A. and O’Donnell F. 1998, ‘A Design Research Approach Presented at AID’98 Workshop on Research Methods in AI in Design', Lisbon, Portugal, 19 July 1998, pp 20-27.

Eraslan, C., Alkis, Z., Emem, O., Helvacı, C., Batuk, F., Gümüsay, U., Demir, T., Turk, T., Bayram, B. and Alkis, A. 2004, 'System design if disaster management information system in Turkey as a part of Egovernment', YTU, Department of Geodesy and Photogrammetry.

Early Warning Network (EWN) 2014, "Free Weather Warnings - Australia - Early Warning System for NSW, QLD, VIC, TAS, SA, NT, WA, ACT, Sydney Weather, Melbourne Weather, Brisbane Weather." Viewed 20 April 2014 <http://www.ewn.com.au/>.

Emergency Alert (EA) 2014, Emergency Alert, viewed 01 May 2014 http://www.emergencyalert.gov.au

Fan, J., Zhang, P., Yen, D.D. 2014, "G2G information sharing among government agencies", Information and Management, 51, pp. 120-128.

Federal Emergency Management Agency (FEMA) 2014, Emergency Alert System, viewed 2 June 2014 <http://www.fema.gov/emergency-alert-system>.

Foster, H. 2013, Interactive hazard preparation strategy efficacy: consideration for future community engagement programs. Australian Journal of Emergency Management, vol. 28, no. 1, pp. 8-14.

Gill, A. \& Bunker, D. 2012. 'Crowd Sourcing Challenges Assessment Index for Disaster Management', AMCIS 2012 Proceedings, Paper 21, viewed 20 April $2014<\mathrm{http} / / /$ aisel.aisnet.org/amcis2012/ proceedings/EGovernment/21>.

Gill, A.Q., Alam, S. and Eustace, J. 2014, Using Social Architecture to Analyzing Online Social Network Use in Emergency Management. Proceedings of the Americas Conference on Information Systems (AMCIS 2014), Savannah, USA.

Gill, A.Q., Alam, S. and Eustace, J. 2015, Social Architecture: An Emergency Management Case Study. Australasian Journal of Information Systems, vo.19, no.1, pp. 23-40.

GovDelivery 2014, Breaking Down Barriers to Effective Emergency Notifications, viewed 01 May 2014, <http://www.govdelivery.com/pdfs/Emergency-Notifications-whitepaper.pdf>. 
Holmes C. 2012, Queensland Floods Commission of Inquiry: Final Report, viewed 20 April 2014 <http://www.floodcommission.qld.gov.au/_data/assets/pdf_file/0007/11698/QFCI-Final-ReportMarch-2012.pdf>.

International Data Corporation (IDC) 2014, IDC Unveils Worldwide Internet of Things Spending Forecast, Vertical Market, viewed 20 April 2014

<http://www.idc.com/getdoc.jsp?containerId=prUS24671614>

Lee, W. B, Wang., Y, Wang., W. M, Cheung., C.F 2012, 'An unstructured information management system (UIMS) for emergency management', Knowledge Management Research Centre, Department of Industrial and Systems Engineering, The Hong Kong Polytechnic University.

Lee, C., Myrick, R., D’Ambrosio, A. L., Coughlin, F. J. \& Weck,L. O. 2013, 'Older Adults' Experiences with Technology: Learning from Their Voices, AgeLab', Engineering Systems Division, Massachusetts Institute of Technology, Cambridge, MA 02139, United States.

Leonardi, C., Mennecozzi, C., Not, E., Pianessi, F., Zancararo, M 2008, 'Designing a Familiar Technology For Elderly People', viewed 14 April $2014<$ www.gerontechnology.info/Journal/Proceedings /ISG08/papers/095.pdf>.

Middelmann M.H. 2007, Natural Hazards in Australia: Identifying Risk Analysis Requirements. Geoscience Australia, Canberra, viewed 20 April 2014 <http://www.ga.gov.au/hazards/our-capabilities/casestudies/natural-hazards-in-australia-report.html $>$.

Morris, M., Ozanne, E., Miller, K., Santamaria, N., Pearce, A., Said, C., Brooke, A., 2012, ‘Smart technologies for older people: a systematic literature review of smart technologies that promote health and wellbeing of older people living at home', Institute for a Broadband-Enabled Society, The University of Melbourne.

NBN 2014, Rollout FAQs, viewed 20 April 2014 <http://www.nbnco.com.au/when-do-i-get-it/about-therollout/faq.html>

Othman, S.H., Beydoun, G. Sugumaran, V. 2014, Development and validation of a Disaster Management Metamodel (DMM), Information Processing \& Management, Volume 50, Issue 2, March 2014, Pages 235-27.

Oloruntoba, R. 2013, 'Plans never go according to plan: An empirical analysis of challenges to plans during the 2009 Victoria bush-fires', Newcastle Business School, Faculty of Business and Law.

Pedersen, J., Kocsis, D., Tripathi, A., Tarrell, A., Weerakoon, A., Tahmasbi, N., Xiong, J., Deng, W., Oh, O. \& Vreede, G. J. G. 2013, 'Conceptual Foundations of Crowdsourcing: A Review of IS Research', 46th Hawaii International Conference on System Sciences (HICSS), pp. 579-588.

RMIT 2011, Systematic review of reports in emergency alert. Prepared for the Office of the Emergency Services Commissioner by the Centre for Risk and Community Safety, RMIT University, viewed 8 April $2014<$ http://www.emergencyalert.gov.au/images/stories/Systematic_Review_of_Reports_ on_Emergency_Alert_December_2011.pdf >

Saunders, E. 2004, 'Maximising computer use among the elderly in rural senior centres', University of Iowa School of Social Work, Iowa City, Iowa, USA, viewed 4 May 2014 <http://www.stanford. edu/group/ecampus/cgi-bin/biblio/node/5929>

The Government of Victoria 2010, 2009 Victorian Bushfire Royal Commission Report, Government Printer, Victoria., viewed 4 June 2014 <http://www.royalcommission.vic.gov.au/finaldocuments/summary/ pf/vbrc_summary_pf.pdf>

Torrens Resilience Institute 2011, Assessment of the Effectiveness of Emergency Alert, Final Report. An Australian Government Initiative, viewed 8 April 2014 <http://www.em.gov.au/Documents/Assessment\%20of\%20the\%20Effectiveness $\% 20$ of $\% 20$ the $\% 20 \mathrm{E}$ mergency\%20Alert\%20Program\%20-\%20Final\%20Report\%20-\%20PDF\%20format\%20V2.pdf>

United Nations (UN) 2012, World Population Prospects: The 2012 Revision, viewed 4 May 2014 <http://esa.un.org/unpd/wpp/Excel-Data/population.htm>

Universidad Carlos III de Madrid (UC3M) 2014, System designed for accessible emergency notifications, viewed 2 June 2014 <http://portal.uc3m.es/portal/page/portal/actualidad_cientifica/noticias/ emergency_notifications>

Van de Watering, M. 2005, The Impact of Computer Technology on the Elderly, view on 20 May <http://www.few.vu.nl/ rvdwate/HCI_Essay_Marek_van_de_Watering.pdf>

Vaishnavi V. and Kuechler W. 2007, 'Design Science Research Methods and Patterns', Innovating Information and Communication Technology, Auerbach Publications 2007.

Wang, S. 1997, 'Modelling information architecture for the organization', Information and Management, 32, pp.303-315. 